\title{
Other Medically Important Serious Event
}

National Cancer Institute

\section{Source}

National Cancer Institute. Other Medically Important Serious Event. NCI Thesaurus. Code C82521.

A serious adverse event that does not meet the criteria for being life threatening, requiring inpatient hospitalization, or causing death, persistent or significant disability or incapacity, cancer, or a congenital anomaly or birth defect, but may require medical or surgical intervention to prevent one or more of those outcomes. 